\title{
The Results of Changing the Current Solution Concept of Universal Motor Gear Reducers with Helical Gears
}

\author{
Milan Rackov ${ }^{1, *}$, Ivan Knežević ${ }^{1}$, Srđan Nikačević ${ }^{1}$, Dijana Čavić$^{1}$, Mirjana Bojanić Šejat $^{1}$, \\ Marko Penčić ${ }^{1}$, Maja Čavić ${ }^{1}$, Siniša Kuzmanović ${ }^{1}$, and Nicolae Florin Cofaru ${ }^{2}$ \\ ${ }^{1}$ University of Novi Sad, Faculty of Technical Sciences, Trg D. Obradovića 6, Novi Sad, Serbia \\ 2"Lucian Blaga" University of Sibiu, Faculty of Engineering, Str. Emil Cioran Nr. 4, Sibiu, Romania
}

\begin{abstract}
By analysing and comparing the existing solutions of universal gear reducers with helical gears of the leading manufacturers, it can be noticed the effort to increase the load capacity of the gear reducer within the same axis height. In this way, the manufacturers can offer smaller (cheaper) gear reducers, as well as to simultaneously increase the values of the largest gear ratios. This concept enables the offer of lower-stage (cheaper) gear reducers with higher gear ratios in certain segments of gear ratios. By these efforts, it is reached the maximum, but the further increase is possible only by changing the current concept of universal gear drives. Within this paper, it is given an overview and analysis of one of the possible new conceptual solutions of modern universal motor gear reducer.
\end{abstract}

\section{Introduction}

Today, almost all manufacturers of universal gear reducers try to increase the load capacity of their gear reducers by applying a larger module, i.e. by reducing the number of teeth of the drive gear, and by increasing the centre distance, i.e. by increasing the diameter of the driven gear, which conditioned the expansion of the housing and its opening (usually from the upper, although it can also be the lower side) so that these large gears could be installed in it. This increase goes only up to a certain limit, which does not require changing the dimensions of the free end of the gear reducer output shaft and the general connection dimensions of the gear reducer, so as not to impair the compatibility of the gear reducer with similar gear reducers from other manufacturers [1]. In addition to increasing the bearing capacity, they also try to increase the highest values of gear ratios, by the same such interventions, and above all by reducing the number of teeth of the first gear (usually to 8) in order to enable the offer of lower (cheaper) gears. Today, single-stage gear reducers are made with gear ratios of up to 15, two-stage and over 80, and three-stage and over 300 [2]. These values, compared to thirty years ago, are three times higher, which indicates the intensive development of these gear reduces. Further improvements are probably not possible without

\footnotetext{
* Corresponding author: racmil@uns.ac.rs
} 
the emergence of new materials for their production, although a change in the concept, which can already be seen in some manufacturers, can expect some further progress in this area [3].

\section{Problem description and analysis}

As for the concept of universal gear reducers, if the production programs of most manufacturers of these gear reducers is analysed, it can be seen that today there are manufacturers who produce special housings for single, two and three-stage gear reduces, which is the best but also the most expensive solution. They make only one universal housing for all these gear reducers. In addition, there are manufacturers who make only one and twostage gear reducers and their connection three-stage, and those who produce one and threestage, and in the housing three-stage and two-stage, as well as those who produce special two-stage and special three-stage gear reducers. Of course, there are also manufacturers who produce only two-stage, as well as those who produce only three-stage, and in their housing also two-stage. Single-stage gear reducers are produced by almost all gear reducer manufacturers, so that the competition is the biggest, and the demand is (relatively) the least. Two-stage gear reducers are also produced by all manufacturers, but those who make them in special housing for two-stage gear reducers have a certain advantage in the area of gear ratios of two-stage gear reducers. Three-stage gear reducers are also produced by all manufacturers, but those who make them in a universal housing for two-stage and three-stage gear reducers, or in special housing for three-stage gear reducers, certainly have a certain advantage in the field of gear ratios of three-stage gear reducers. Which solution to adopt is a big dilemma for every gear reducer manufacturer, and the choice of solution depends on his experience, ambitions, financial capabilities and, most of all, on the needs of the market [4].

Single-stage gear reducers are made in two basic versions: with a driven gear (output shaft) placed below (Fig. 1-1), which allows them to be connected to relatively large electric motors, and with a driven gear (output shaft) placed above (Fig. 1-2). When using large electric motors, if the reducer is supplied with the feet, special foundation preparation is required. It is necessary to emphasize that the solution, with the output gear placed above, is very rare in practice. In both cases, the sizes of the driven gears, and thus the gear ratios, are limited by the axis height of the gear reducer as well as the connecting dimensions of the electric motor.

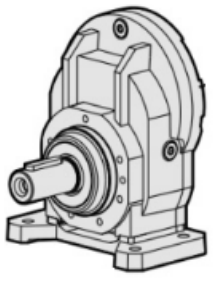

1

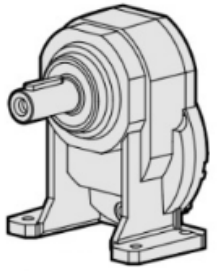

2

Fig. 1. Typical solutions of single-stage universal gear motors: (1) with feet and lower output shaft position, (2) with feet and upper output shaft position, Motovario solutions [5]

Unlike single-stage gear reducers, with two- and three-stage gear reducers, the driven gear (output shaft) is almost always mounted upwards (Fig. 2 - 1, 2, 3) to allow easy connection to large electric motors. However, today, even higher gear ratios and even higher load capacities should be achieved within the same axis height of gear reducers. Some manufacturers abandon the usual concept of two-stage gear reducers and try to solve the 
problems with low load capacity and small gear ratios using large output gear positioned in the bottom, similar as in single-stage gear reducers (Fig. $2-4,5$ ).

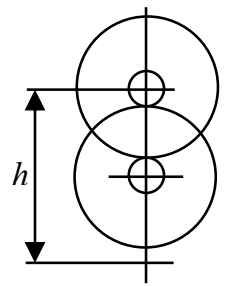

1

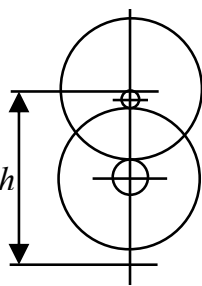

2

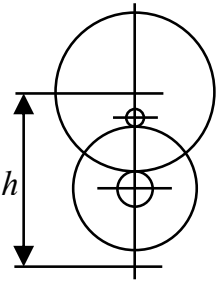

3

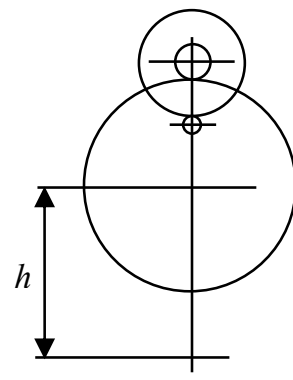

4

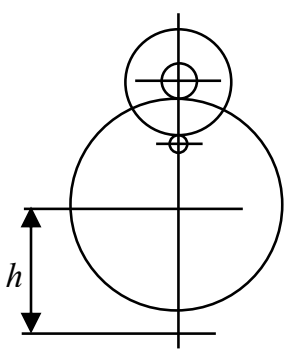

5

Fig. 2. Schematic representation of the way to increase the gear ratio and load capacity of a two-stage gear reducer with helical gears

The usual arrangement of gears, in the classic solution of a two-stage universal gear reducer with helical gears, is shown in Fig.2-1. Production of small pinions with only 7 or 8 teeth gives significant positive effect in this improving of gear ratio. Increasing of only axial distance can give similar results, but this requires additional expansion of gear unit housing as well as widening of the openings in the housing (to mount large gear wheel). In the case of applying small pinions and larger axial distance, it is possible to significantly increase the largest gear ratio values, which is most commonly done today. By changing the concept of the pinion, i.e. using the pinion with a smaller number of teeth and a smaller diameter (Fig. $2-2$ ), which is pressed into the shaft of the electric motor, affected the abandonment of the concept of coaxial gears. It is not possible to increase the diameter of the second gear without changing the axis height of the gear reducer, which would reduce its gear ratio, which would lead to the "entry" of higher torque into the gear reducer, which would require the strengthening of all components within the gear reducer. In order to further increase the gear ratios and at the same time increase the load capacity, and "let" as little torque as possible into the gear reducer, the centre distance of the output pair was increased. The diameter of the fourth gear was increased, which influenced the reduction of the load of the first pair and enabled the application of a weaker (smaller) first pair (Fig. 2-3). In case of increasing the gear ratio even more, that is, the load capacity of the gear reducer, it is necessary to additionally increase the fourth gear, and place the input pair above the output shaft (Fig. 24). This significantly increases the overall dimensions of the gear reducer, and since there is a lot of empty space under the gears, two solutions are possible:

- First, the production of a universal housing, suitable for connection with the feet and the flange, which is especially interesting for smaller manufacturers because it achieves a more rational (cheaper) solution of the gear reducer housing (Fig. 3-1) and

- The second solution, which is reflected in the reduction of the axis height of the gear reducer (Fig. 2-5), which would, at a lower axis height, achieve a significantly higher load capacity (by one row) with slightly larger overall dimensions of the gear reducer. However, the offer of a stronger gear reducer, with a larger output shaft diameter, would not ensure full compatibility of gear reducers with gear reducers from other manufacturers, which would, due to the change of connection dimensions, most likely slightly reduce their placement, but due to higher load capacity, within the same axis height, on the whole it certainly grew. 
An overview of the characteristic sizes of two- and three-stage gear reduces (Table 1) shows that by placing the output gear down (REGAL's solution) the highest value of gear ratios increased, although some manufacturers with the classic gear reducers concept achieve similar and even higher gear ratio values. However, the loads of such reducers are significantly higher so this procedure seems to be fully worthwhile. In addition, its main advantage is that it allows easy installation of the feet, i.e. the possibility of using a universal housing for connection via a flange and over the foot and that the same housing is used for both single-stage and two-stage and three-stage gear reducers. This is extremely important for smaller manufacturers because it does not require the manufacture and storage of six types of housings.

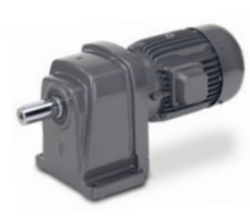

1

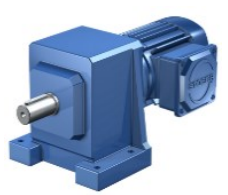

2

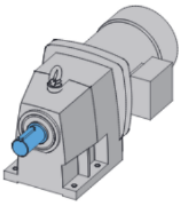

3

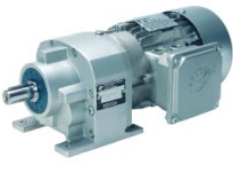

4

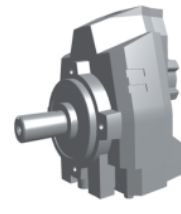

5

Fig. 3. Characteristic solutions of two-stage motor gear reducers, which are built in special housing for two-stage gear reducers, (1) solutions with rear opening BEGE [6], (2) STÖBER [7], (3) NORD [8], (4) solution in universal housing for two- and three-stage gear reducers NORD [9] and (5) solutions in universal housing for single, two-stage and three-stage gear reducers with opening down REGAL [10]

Table 1. Overview of characteristic sizes of universal gear motor gear reducers with axis height

$$
\mathrm{h}=130 \mathrm{~mm} \text {. }
$$

Two-stage gear reducers that are built in special housing for two-stage gear reducers and three-stage gear reducers that are built by connecting two and one-stage gear reducers:

\begin{tabular}{|c|c|c|c|c|c|c|c|}
\hline \multirow{2}{*}{$\begin{array}{c}\text { Gear reducer } \\
\text { manufacturer } \\
\text { and type }\end{array}$} & \multirow{2}{*}{$\begin{array}{c}\text { Axis } \\
\text { height } \\
\mathrm{h}, \mathrm{mm}\end{array}$} & \multirow{2}{*}{$\begin{array}{c}\text { Diameter } \\
\mathrm{d}, \mathrm{mm}\end{array}$} & \multirow{2}{*}{$\begin{array}{c}\text { Total } \\
\text { height }\end{array}$} & \multicolumn{2}{|c|}{$\begin{array}{c}\text { Two-stage gear } \\
\text { reducer }\end{array}$} & \multicolumn{2}{|c|}{$\begin{array}{c}\text { Three-stage gear } \\
\text { reducer }\end{array}$} \\
\cline { 5 - 9 } & & $\mathrm{H}, \mathrm{mm}$ & $\mathrm{i}_{\min }-\mathrm{i}_{\max }$ & $\begin{array}{c}\mathrm{T}_{2 \mathrm{~N}}, \\
\mathrm{Nm}\end{array}$ & $\mathrm{i}_{\min }-\mathrm{i}_{\max }$ & $\begin{array}{c}\mathrm{T}_{2 \mathrm{~N}}, \\
\mathrm{Nm}\end{array}$ \\
\hline BEGE, G22/220 & $125^{*}$ & 25 & 206 & $4.50-55.49$ & 175 & $34.1-431.15$ & 175 \\
\hline $\begin{array}{c}\text { STOBER, } \\
\text { C302/3 }\end{array}$ & 130 & 30 & 215 & $2.02-69.88$ & 400 & $80.43-273.7$ & 400 \\
\hline NORD, SK22/3 & $125^{*}$ & 30 & 225 & $2.79-86.3$ & 340 & $64.8-516.65$ & 340 \\
\hline REGAL, 702/3C & 130 & 35 & 290 & $6.57-71.25$ & 675 & $61.89-561.7$ & 675 \\
\hline
\end{tabular}

Two- and three-stage gear reducers that are built in a universal housing for two- and three-stage gear reducers:

\begin{tabular}{|c|c|c|c|c|c|c|c|}
\hline $\begin{array}{c}\text { NORD, } \\
\text { SK672/3 }\end{array}$ & 130 & 35 & 232 & $2.66-56.65$ & 610 & $22.8-362.43$ & 640 \\
\hline
\end{tabular}

Note: The manufacturer marked with star does not produce the axis height reducers

It should be noted that some manufacturers, who make universal gear reducers in a universal housing for two and three-stage gear reducers, can also achieve similarly, or slightly lower, values of load capacity and gear ratios, which leads to the conclusion that the use of gear reducers with output gear set down, justified only by the possibility of its simple connection with the feet and the flange, ie. due to the possibility of using only one connection housing via the foot and the flange.

However, lowering the axis height of the gear reducer (Table 2) would achieve more significant effects but would somewhat impair the compatibility of the gear reducers. Buyers who would decide to buy smaller gear reducers would not be able, without changing the 
diameter of the output shaft, to use gear reducers from other manufacturers. This intervention would force other manufacturers to offer higher load capacity and other shaft dimensions within a lower axis height, although even today there are manufacturers that within some of the standard axis heights offer different loads than usual and even have different axis heights than usual.

So, by changing the concept, significant effects can be achieved, either due to the possibility of using only one universal housing for connection to the flange and feet, or due to the possibility of lowering the axis height and thus raising the load capacity of the gear reducer within that new axis height.

Table 2. Overview of characteristic sizes of universal gear motor gearboxes with axis height $\mathrm{h}=115 \mathrm{~mm}$

Proposed solution with reduced axis height and classic housing with feet / flange

\begin{tabular}{|l|l|l|l|l|l|l|l|}
\hline- & 115 & 35 & 275 & $6.57-71.25$ & 675 & $61.89-561.76$ & 675 \\
\hline
\end{tabular}

Two-stage gear reducers that are built in special housing for two-stage gear reducers and three-stage gear reducers that are built by connecting two and single-stage gear reducers:

\begin{tabular}{|c|c|c|c|c|c|c|c|}
\hline \multirow{2}{*}{$\begin{array}{c}\text { Gear reducer } \\
\text { manufacturer } \\
\text { and type }\end{array}$} & \multirow{2}{*}{$\begin{array}{c}\text { Axis } \\
\text { height } \\
\mathrm{h}, \mathrm{mm}\end{array}$} & \multirow{2}{*}{$\begin{array}{c}\text { Diameter } \\
\mathrm{d}, \mathrm{mm}\end{array}$} & \multirow{2}{*}{$\begin{array}{c}\text { Total } \\
\text { height }\end{array}$} & \multicolumn{2}{|c|}{$\begin{array}{c}\text { Two-stage gear } \\
\text { reducer }\end{array}$} & \multicolumn{2}{|c|}{$\begin{array}{c}\text { Three-stage gear } \\
\text { reducer }\end{array}$} \\
\cline { 5 - 9 } & & $\mathrm{H}, \mathrm{mm}$ & $\mathrm{i}_{\min }-\mathrm{i}_{\max }$ & $\begin{array}{c}\mathrm{T}_{2 \mathrm{~N}}, \\
\mathrm{Nm}\end{array}$ & $\mathrm{i}_{\min }-\mathrm{i}_{\max }$ & $\begin{array}{c}\mathrm{T}_{2 \mathrm{~N}} \\
\mathrm{Nm}\end{array}$ \\
\hline $\begin{array}{c}\text { BEGE}, \\
\text { G22/220 }\end{array}$ & $125^{*}$ & 25 & 206 & $4.50-55.49$ & 175 & $34.1-431.15$ & 175 \\
\hline $\begin{array}{c}\text { STOBER, } \\
\text { C202/3 }\end{array}$ & 115 & 30 & 195 & $5.79-70.32$ & 230 & $79.59-275.4$ & 230 \\
\hline $\begin{array}{c}\text { NORD, } \\
\text { SK22/3 }\end{array}$ & $125^{*}$ & 30 & 225 & $2.79-86.3$ & 340 & $64.8-516.65$ & 340 \\
\hline $\begin{array}{c}\text { REGAL, } \\
502 / 3 C\end{array}$ & 115 & 30 & 242 & $8.38-85.19$ & 320 & $74.3-356.09$ & 320 \\
\hline
\end{tabular}

Two- and three-stage gear reducers that are built in a universal housing for two- and three-stage gear reducers:

\begin{tabular}{|c|c|c|c|c|c|c|c|}
\hline $\begin{array}{c}\text { NORD, } \\
\text { SK572/3 }\end{array}$ & 115 & 30 & 208 & $2.92-54.41$ & 400 & $17.42-402.8$ & 450 \\
\hline
\end{tabular}

*Note: The manufacturer marked with star does not produce the axis height reducers

Offering such a powerful gear reducer would certainly achieve significant effects, although these gear reducers would initially be slightly more expensive than the competition due to the use of a large output gear and a slightly larger housing, but a smart pricing policy could overcome this.

\section{Solving the problem}

In the proposed solution of gear reducers with a special housing for two-stage gear reducers, with an opening on the bottom, only one output pair with a large gear ratio could be used (due to its price) and by applying the first pair with different gear ratio values, according to the standard order R20, provided it would be possible to achieve gear ratio in two and threestage variants in the same order (Fig. 4).

Since it is now practised to cover small gear ratios with multistage gear reducers, many manufacturers also practice having gear pairs that work as multipliers within single-stage gear reducers (shown in the figure by a dashed line). 


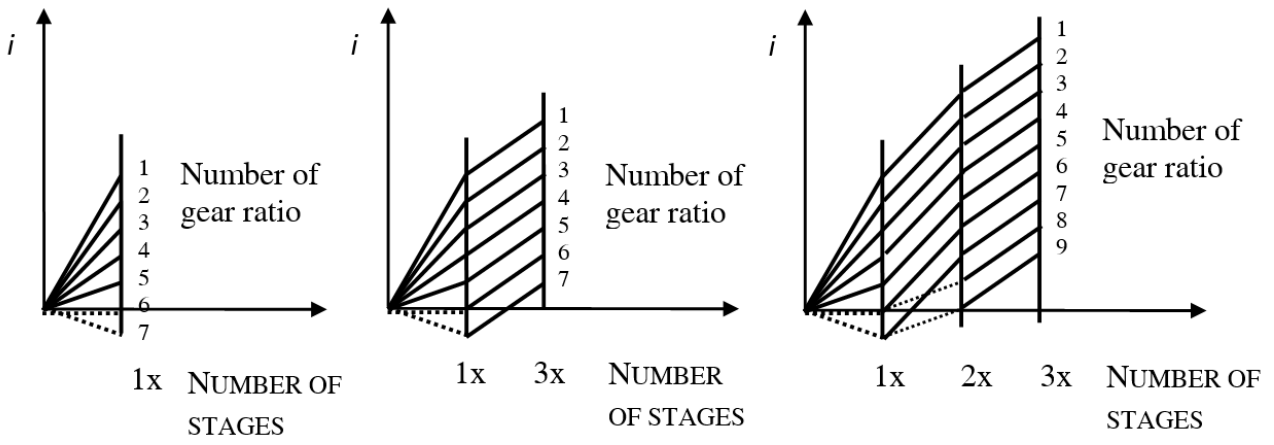

Fig. 4. Graphical representation of the manner of realization of different gear ratios within (1) one, (2) two and (3) three-stage gear reducers.

\section{Conclusion}

Based on the performed design solutions of gear reducers, it can be concluded that further development and new design solutions can be expected. Changing the concept of universal gear reducers, i.e. by placing the output shaft down (as with single-stage gear reducers), certain effects could be achieved, which are reflected in the application of a universal solution housing with feet and flange, or can be achieved significantly higher load capacity within the first smaller size, which would certainly have a favourable effect on the placement of universal gear reducers. In addition, such an approach could use the same housing, as REGAL [10] does, to make single, two and three-stage gear reducers.

Acknowledgment: This paper has been supported by the Ministry of Education, Science and Technological Development through project no. 451-03-9/2021-14/200156: "Innovative scientific and artistic research from the FTS (activity) domain".

\section{References}

1. Ž. Zadnik; M. Karakašić, M. Kljajin, J. Duhovnik, SV - JME, 55, 7-8 (2009)

2. S. Kuzmanović, M. Rackov, I. Knežević, M. Vereš, KOD'16, Analysis of Selection Procedures of Universal Worm Gear Units, (Balatonfured, Hungary, 2016)

3. M. Rackov, S. Kuzmanović, M. Blagojević, Z. Đorđević, Motor Gear Reducers with Cylindrical Gears (Faculty of Technical Sciences, Novi Sad, 2019)

4. M. Rackov, Conceptions of Development of Universal Gear Reducers (PhD thesis in Serbian), (the University of Novi Sad, Faculty of Technical Sciences, 2013)

5. Helical Geared Motors, Motovario S.p.A., H/2018/Rev.0

6. BEGE Power Transmission, Catalogue no. 241704, Helical Gear Motors, Sassenheim, Netherlands

7. SMS/MGS Gearunits, Catalogue 11, STÖBER Antriebstechnik GmbH \& Co. KG.

8. NORD Drivesystems, Standard Helical Gearboxes, G 2018, Getriebebau Nord, Hamburg

9. NORDBLOC.1® Helical In-Line Gear Units, 100200108 / 0517

10. Marathon Gearboxes Inline Coaxial Catalogue, Regal Beloit Australia Pty Ltd (2016) 